LAW, ETHICS AND MEDICINE

\title{
The convention on human rights and biomedicine and the use of coercion in psychiatry
}

\section{T Tannsjo}

\begin{abstract}
According to a recent convention on human rights and biomedicine, coercive treatment of psychiatric patients may only be given if, without such treatment, serious harm is likely to result to the health of the patient; it must not be given in the interest of other people. In the present article a discussion is undertaken about the implication of this stipulation for the use of coercion in psychiatry in general and in forensic psychiatry in particular.
\end{abstract}

1 is a little publicised fact that the Committee of Ministers of the Council of Europe adopted a new document, the Convention on Human Rights and Biomedicine, on 19 November 1996 (hereafter, the convention, for short). ${ }^{1}$ Even the US, Australia, Canada, and Japan have contributed to the convention so legislative bodies in these countries will have to take a stand on it as well, which means that it will come to have worldwide importance. Just one aspect of the convention has attracted public attention. This is the unfortunate article 18, dealing with research on embryos in vitro, where it is stated that the creating of human embryos for research purposes is prohibited. This article means there are problems for countries such as the UK and Sweden, where therapeutic cloning is accepted (no one had thought of therapeutic cloning when the article was formulated). Other aspects of the convention have, however, been little discussed. (There are some exceptions to this rule, of course. Two such exceptions are provided by Rosenau ${ }^{2}$ and Dommel, et al. ${ }^{3}$ ) This is a pity, since, in many respects the convention is an admirable document. I have discussed it at length in my book Coercive Care. ${ }^{4}$ Here I will focus on its implications for the use of coercion within psychiatry. In the convention the following statement is made:

Subject to protective conditions prescribed by law, including supervisory, control, and appeal procedures, a person who has a mental disorder of a serious nature may be subjected, without his or her consent, to an intervention aimed at treating his or her mental disorder only where, without such treatment, serious harm is likely to result to his or her health. ${ }^{1}$

Now, since the convention has not yet been accepted, approved, or ratified (these are the three possible options offered) by the member states, and since it is possible for a member state to make a reservation in respect of any particular provision of the convention which does not conform to any law then in force in its territory, and since article 26 of the convention allows for restrictions of the exercise of the rights defined in the convention, it is doubtful what legal impact the convention will have. Let us set these practical difficulties to one side, however, and ponder what it would mean if, all over the world, the convention were to be taken seriously.

The most remarkable fact about the clause just quoted is that, according to that clause, coercive treatment may only be given if, without such treatment, serious harm is likely to result to the health of the patient; it must not be given in the interest of other people (such as close relatives, or the public at large). In this the paragraph differs from what is stipulated in an earlier recommendation (No R(83) 2) adopted by the Committee of Ministers of the Council of Europe on February 22, 1983, Legal Protection of Persons Suffering from Mental Disorder Placed as Involuntary Patients. According to article 3 of this recommendation:

a patient may be placed in an establishment only when, by reason of his mental disorder, he represents a serious danger to himself or to other persons. ${ }^{5}$

It might perhaps be objected that while the convention speaks only about coercive treatment, article 3 here speaks of coercive confinement. Is the convention intended to cover confinement as well? This is hard to tell, of course, since the convention is a political document. For reasons to be spelled out later on, however, allow me to make a strong interpretation of the convention, whereby I take the clause to cover both coercive treatment and confinement. In my opinion, this is the most enlightened interpretation of this clause, and it is interesting to see what implications this interpretation would have.

Many actual laws in the US and European countries are at variance with this new requirement of the convention particularly if interpreted in the strong way I suggest here. To my knowledge, only Italy and Sweden have legislation in line with this clause. It seems, however, as though Ontario (since the mid-1980s) and some other Canadian provinces have taken some steps in the same direction. In Ontario a capacity standard is used, and, while patients can be 
confined because they are dangerous to others, they cannot be coercively treated on this account. ${ }^{*}$

Suppose the rest of the world would like to follow suit. What problems will emerge? How could these problems be solved? In order to answer these questions, a more general treatment of the place of coercion within psychiatry must be given. I will here give such an answer, bearing in mind that I am interpreting the convention in the strong manner indicated above.

Three questions need to be addressed: on what grounds should patients who need psychiatric treatment, but who do not consent to be treated, be (confined and) treated? What kind of treatment should be offered to them? And what are we to do about people who are dangerously insane?

I will discuss these questions in order, on the assumption that we want to live up to both the letter and spirit of the convention.

\section{THE GROUNDS FOR COERCIVE TREATMENT}

First of all, it could be held that people suffering from a mental illness, who need medical treatment for it, and who do not assent to the treatment, should be coercively treated for their illness. This is a model which takes advantage of all the scope for coercion allowed for by the convention. I refer to this as the need model. ${ }^{4}$ This model is being followed in Sweden and Italy.

Both Swedish and Italian law stress the fact that it is solely the need of the patient that warrants commitment, not the interest of other people. Many other countries mentioned here use the need model but go beyond it, in committing people who are dangerous to others as well. This is true-for example, of the US. Russian law is special in that it allows for people to be committed on grounds of "helplessness", as well as on strict medical grounds (mental illness). ${ }^{6}$

Secondly, a narrower model would be one whereby only people who suffer from mental illness, who need medical treatment for it, whose lives are put at risk if they are not treated, and who do not assent to the treatment, should be coercively confined and treated for their illness. I refer to this as the life rescue model. German law-for example, stipulates that a person who does not consent to treatment must not be committed in his own interest unless he poses a threat to his own life. German law, however, as do laws in most countries, also allows people suffering from mental illness to be committed on the grounds that they pose a threat to others. This goes beyond the life rescue model, as it is here defined.

Finally, a third model would be one whereby only people who suffer from mental illness, who need medical treatment for it, who are not capable of making an autonomous decision about their medical needs, and who do not assent to the treatment, should be coercively treated for their illness. I refer to this model as the incompetency model.

The incompetency model is not practised in any country or state I know of, even if some US states use the reference to incompetency as one criterion among others. Now, which model is preferable?

I have difficulties accepting the life rescue model. If a treatment exists, and a person needs it (even if the need is not a matter of life and death, but that person cannot make an autonomous decision, then it would be wrong not to coerce the person into accepting the treatment in question, irrespective of the grounds for the incompetency of that person. It seems to me utterly complacent not to treat a patient who is in need of treatment but who, because of mental illness, does not understand this. To safeguard a person's health may be just as important as to save his or her

*I owe this observation to an anonymous referee for this journal. life. For, certainly, a life with severe mental illness may be a life not worth experiencing. To substantiate this point it would be necessary to go deeply into difficult axiological problems. On the hedonistic view I defend in my book Hedonistic Utilitarianism, this claim should not be very controversial. $^{7}$

If we reject the life rescue model, should we then go all the way and adopt the need model? I think not. Note that, even if, in an individual case, it may seem complacent not to treat a competent patient against his or her wish, provided treatment is what this patient needs, this is standard procedure in somatic medicine. In somatic medicine we treat patients without their consent, if we cannot obtain it (because the patients are, say, in a coma). We treat them on the reasonable presumption that this is what they would have wanted, had they been able to communicate their wish to us. If, however, they are competent, and reject treatment, their wish is honoured. So why should it not be standard procedure also within psychiatry?

If a competent person rejects a treatment, we have good reasons to suspect that the treatment may not, after all, be in the best interest of the patient. After all, the patient has an epistemologically privileged perspective on his or her own life, and a special interest in it as well. There may be a rationale behind his or her decision, a rationale that we have not fully comprehended. So the presumption should always be that a well informed and competent patient knows what is best for him. And, even if, in a singular case, this presumption is wrong, there are indeed very bad side effects associated with using any kind of coercion.

The use of coercion against competent patients may mean that the general trust in the health care system withers. Patients may begin to hesitate about seeking help when they have medical problems. This is true no less of psychiatry than of health care in general. Remember that, even if it means certain death for the patient, a Jehovah's Witness is permitted to reject blood transfusions.

Furthermore, one more reason to opt for the competency model is that, while the need model is at variance with the Declaration of Hawaii, the competency model is compatible with it. In article 5 of this declaration it is stated:

No procedure shall be performed nor treatment given against or independent of a patient's own will, unless because of mental illness, the patient cannot form a judgment as to what is in his or her own best interest and without which treatment serious impairment is likely to occur to the patient or others. ${ }^{8}$

It should also be noted that, coercively treating an incompetent person who needs treatment, is not at variance with any plausible principle of respect for the autonomy of the individual in decisions about medical care and social services. For, when such coercion is exercised, it is reasonable to assume that the coerced person, if capable of making an autonomous decision, would assent to it.

It might be thought, however, that while it is reasonable to abide by the principle of respect for the autonomy of the individual in decisions about medical care and social services in relation to bodily health care, the principle cannot be applied to mental illness. Mental illness is different, it might be held. Mentally ill persons must be guarded also against their autonomous decisions. Mentally ill persons do not know their own best interests. With respect to mentally ill persons, only the need model is justifiable.

For all its popularity, we ought to resist this argument (which provides the rationale behind-for example, Swedish legislation in this field). It might be argued of course that, 
unless we protect mentally ill persons against their misapprehensions of their situation, even when they are capable of exercising an autonomous decision, they would harm themselves. They do not know their own best interests. Unless we stop some of them, for example, they will give away everything they own, or, unless we lock up others among them, they will kill themselves. If we protect all these people from harming themselves we help them to sustain a prosperous and perhaps long life, once they are cured of their illness. In the future, they may even themselves come to thank us for having done so.

This is not convincing. At least in a civilised society, a grown up and competent person should be allowed to give away all his or her property, and yet, for all that, live a decent life. If necessary, the social services should see to this.

Also, a person capable of exercising an autonomous decision ought to be allowed to kill him or herself. After all, even if mentally ill, he or she has a privileged position when it comes to judging the value of his or her life. And no one, at least no doctor or social worker, has any stake in the outcome that can compete with the person's own.

The upshot of this is that a person who is in the grip of an acute psychosis may be confined and treated, against her will, for the psychosis. Once the acute psychosis is over, however, and she can make an autonomous decision, she should be allowed to decide autonomously whether to go on with the treatment.

This person should even be allowed to commit suicide, if this is the option chosen. A mentally ill person may have very good reasons indeed to commit suicide.

\section{WHAT KIND OF TREATMENT SHOULD BE PROVIDED}

It is one thing to say that people who need psychiatric care, who are not capable of reaching an autonomous decision about the care, and who refuse to accept the care needed, should be compulsorily committed to a closed ward in a psychiatric hospital, and quite a different thing to say what kind of medication should be administered to them, while they are detained. So the question needs to be addressed: what kind of medication should be given to them?

In the first place, these people should be protected against themselves. They should, while in the grip of their psychosis, be stopped from committing suicide, or from otherwise hurting themselves. To the extent that medication is needed, it must be administered. This is not controversial.

Secondly, these people should be treated, not only in order to keep them alive, but also with whatever medication is considered necessary to restore the capacity to make autonomous decisions, at least unless there exists a prior and competent refusal for such treatment. I will return to this subject. This too should not be very controversial.

Note that all this is well in line with how medication is given for bodily symptoms-for example, in emergencieswhen no consent can be obtained from the patient. And it is in line with article 8 of the convention:

\section{When, because of an emergency situation, the appro- priate consent cannot be obtained, any medically necessary intervention may be carried out immediately for the benefit of the health of the individual concerned. ${ }^{1}$}

The crucial thing here is not really that what we are facing is a situation of emergency. It is rather the urgent medical need in a situation where the patient cannot consent to treatment that provides the rationale behind the medical intervention. So it seems only reasonable to allow this kind of reasoning to apply also to mental illness. However, no other kind of medication should be coercively or manipulatively given for mental illness.

The reason for this restrictive use of compulsory medication for mental illness should be rather obvious. On the competency model, once the patient is capable of making an autonomous decision, it is up the patient, not the caregiver, to decide what kind of medication should be administered.

This is how cures for diseases of the body are administered: the patient is granted an absolute right to veto medication. There is no reason to treat cures for mental illness any differently.

As a matter of fact, there are special reasons to treat medication for mental illness more, rather than less, restrictively. This is to do with the fact that medication for mental illness is much more controversial than medication for somatic problems. Medication for mental illness has been questioned on at least two main counts.

On the one hand, it has been questioned on grounds of efficiency. The causes behind mental illness are not very well known. Consequently, it is a moot question to what extent medication cures mental diseases, or even renders less serious the symptoms of mental illness.

On the other hand, medication for mental illness has been questioned on the (moral) ground that it may be only too effective, in that it changes the personality of the person suffering from the illness. If this kind of medication, namely medication which changes the personality of the patient is undertaken coercively, it may constitute a serious assault on the patient.

I do not say that, upon closer examination, any of these arguments are sound. The mere possibility, however, that any of them might be sound, (and, actually, the very suspicion that any of them might be sound) is a good reason against coercively (and unnecessarily) medicating patients suffering from mental illness.

The decision to use whatever medicine might, according to the doctor, be indicated, should be placed in the hands of the patient, once the patient is capable of making an autonomous decision. Mental illness should be treated no differently from somatic disease in this respect.

As a matter of fact, when a patient has been coercively committed, there exists a special risk of which the caregiver must be keenly aware. The risk is that the patient who has been committed against his will, will give up his own judgment, once detained. He may come to agree to a treatment he would have rejected, had he dared, or found it worthwhile, to voice an opinion.

Does this mean that certain kinds of medication or treatment (such as ECT) should be explicitly forbidden? Does it mean that special rules should apply to clinical trials where compulsorily admitted patients are involved?

I think not. The crucial question here is whether these kinds of treatment and medication are acceptable at all. So if valid criticism can be put forward against their use, this should be a reason for not using them in psychiatric treatment in general, and not only in the particular cases where the treatment takes a coercive form.

Note, however, that if a psychotic person has declared, in a living will, when she was not psychotic, that she does not want under any circumstances to have a certain kind of treatment, such as ECT or a certain drug, then this wish of the patient should be honoured even when she is psychotic. Once again, we should treat mental illness no differently from how we treat bodily illness. All this is well in line with the convention. This way of handling controversial therapies should be an incentive for the medical and scientific society to try to find out whether these controversial therapies are really efficient, and whether there are really no better options available or capable of being developed. 
While clinical trials may be acceptable, being in the best interests of the patients who are coercively detained, no experimentation, involving any risk at all, no matter how small, but where there is no possible benefit to the patient, should be allowed to take place with these patients, not even with their "consent". In this I find the convention too liberal. According to article 17 of the convention, under exceptional circumstances, research with no potential to produce results of direct benefit to the health of a person concerned, who is not competent to decide for herself, may be conducted. It may be conducted if the person in question does not object and, if certain other provisions are met, the most important one being the following:

the research has the aim of contributing, through significant improvement in the scientific understanding of the individual's condition, disease or disorder, to the ultimate attainment of results capable of conferring benefit to the person concerned or to other persons in the same age category or afflicted with the same disease or disorder or having the same condition.'

The reason for thinking this too liberal, and for wanting an absolute restriction in this field, is simple: the consent of these people, even if it can be gained, cannot be assumed to be a true expression of their autonomous will.

Note that there is no solid ground for presumed consent in this area. For it is one thing to presume that a certain individual would have accepted the best possible treatment, if he had been capable of considering the problem rationally, and quite a different thing to presume that a certain individual would have volunteered for an experiment, for the sake of science or the wellbeing of other persons, if he had been capable of considering the offer rationally. We can have good reasons for the former presumption (when ill, people in general want to be cured), but never for the latter presumption (people typically differ with respect to their degree of willingness to make sacrifices for the sake of others).

\section{WHAT ARE WE TO DO WITH THOSE WHO ARE DANGEROUSLY INSANE?}

Some people who suffer from a mental disorder are dangerous to others. Some of them, influenced by their mental illness, commit crimes. If we are not allowed to treat people for their mental disorder on the grounds that they are dangerous to others, what are we to do with these people?

Some of these people can be treated for their own sake, of course, but what if there is no cure available for them? The only way to abide by the convention when dealing with these people, it seems to me, would be to hold them responsible when they have committed a crime, and sentence them to jail.

Of course, if they have a mental disorder for which there is a cure, they should be offered this cure on a voluntary basis (they should be taken out of jail to receive the treatment and then returned to prison when the cure has been finalised). And if they need treatment in their own best interests, but are incompetent, they should be coercively treated, on the presumption that this is what they would have asked for, had they been able to make an autonomous and well informed request.

I have named the model just described the "full responsibility model", and I am sorry to say that I know of no place where it is practised. If we want to abide by the convention, however, there seems to be no way of avoiding the full responsibility model.
If we want to defend the full responsibility model, we have to resist three arguments. I have discussed them at length elsewhere, and I will only gloss over them in the present context. ${ }^{4}$ These are the argument from retributive justice, the argument from jeopardy, and the argument from humanity.

According to the argument from retributive justice it is surely unjust to punish people who cannot help doing what they do.

No, I submit, it is not. This argument depends on an untenable idea of retributive justice according to which there is such a thing as a just and deserved punishment. We should reject the very notion of a just punishment.

According to the argument from jeopardy, however, should we really release a mentally ill person once he has served his time? What if he is still dangerous?

The answer to this argument is as follows: we sentence people who have committed violent crimes to very long times in prison, but we release them on parole, if and once it has proved reasonably safe to do so. We do this irrespective of the grounds on which they have been considered dangerous. Hence, we do not treat mentally ill prisoners any differently from how we treat other prisoners.

However, finally, and according to the argument from humanity, is it not inhumane to put mentally ill people in prison? Is it not inhumane to them as well as to the other inmates?

I think not, provided we are prepared to spend necessary the economic resources on prisons, making certain that all the individual needs of the prisoners are met. In all affluent societies this is a real possibility, a mere matter of political preference.

If we put the discussion of these objections to one side, we may instead focus on the positive aspects of the full responsibility model.

First of all, if we stick to the convention and adopt it, we get a clear delineation of roles, which engenders a more professional approach to treatment. We allow the psychiatrist to be just a doctor, not a warden. We allow that punishment is one thing, treatment another.

Secondly, on the full responsibility model, we liberate psychiatry from the responsibility of deciding if people who were mentally ill when they committed criminal offences "could have acted otherwise" - a hopeless task (the philosopher knows).

Thirdly, on the full responsibility model we allow psychiatrists to live up to, not only the requirements of the convention, but also to their aforementioned professional ethical code (the Declaration of Hawaii), which they cannot do if they accept that they must detain those who are dangerously insane.

On all other known and used models, psychiatrists have to flout their professional code (the Declaration of Hawaii). They have to do this because, in many situations, they find that there is no more treatment they can offer their patient and yet, for all that, the legal authorities demand that they go on with their "cure". This is because, after the patient has been considered unfit to stand trial, and been given all treatment there is to give, the patient is still considered dangerous to others. To abide by such a ruling of a court of law is, however, inconsistent with what is stated in article 7 of the Declaration of Hawaii:

If a patient or some third party demands actions contrary to scientific knowledge or ethical principles the psychiatrist must refuse to cooperate (Declaration of Hawaii, ${ }^{8}$ art 7).

James C Beck has made the following comment about this, relating to US practice: 
Incompetent defendants who do not meet civil commitment standards are to be released from hospital. However, judges are reluctant to release incompetent patients charged with serious violent crimes. Often, judges will find that these patients meet standards for commitment on evidence which would not be sufficient for commitment of other persons ( $p$ 17). ${ }^{10}$

Also, another expert on forensic medicine, Lars Lidberg, has noted that the professional medical judgment of forensic psychiatrists tends to become corrupted by the lack of a clear delineation between punishment and cure; we can see this from the following observation:

In spite of the fact that there are vast differences between different countries in how long a certain psychiatric disease will be treated, there is a common denominator. How long a person, in a certain country, will be subjected to civil commitment after having committed a certain crime corresponds amazingly well with how long time a person, who has been convicted in the same country for the same crime, will have to serve in prison. ${ }^{11} \dagger$

Fourthly, and consequently, on the full responsibility model, by allowing psychiatrists to abide by the Declaration of Hawaii, and to act according to their professional judgment, we improve their reputation, which at present is bad. By giving them a strictly medical role, outside the repressive system of punishment, we make it possible for their patients to have faith in them, in a way that is not possible when the psychiatrists are part and parcel of the repressive system.

Finally, on the full responsibility model, we treat mentally ill persons as "normal"; we allow them to repent their crimes, which makes their recovery easier. In this way all sorts of prejudice against those who are mentally ill can be counteracted. This also makes it easier for them to return to society, once they have served their time. In particular, if they are quickly cured and released (because they have been quickly cured) after having committed horrible crimes, it is more than likely that people in general will look askance at them. If, instead, they have both been cured and served some time for their crimes, people will find it easier to forgive them for what they have done.

\section{CONCLUSION}

I realise that my proposal that the sole legitimate ground for compulsorily committing people for psychiatric treatment be

†This work is translated by the author from Swedish. their own need for the treatment in combination with their incompetence-the incompetency model, is somewhat controversial. (Though it is less radical than some proposals from the "antipsychiatric" movement initiated by Thomas Szasz.) Also I realise that my proposal that people who have committed crimes under the influence of mental illness be put into prison-the full responsibility model, is very controversial indeed. I must concede that it is not likely that these proposals will become actual law in many countries in the near future. If, however, we want to live up to both the letter and the spirit of the convention, which states that people may only be committed to psychiatric treatment if this is what they themselves need, we have no option but to accept these proposals. Moreover, there are some good reasons for accepting each of them, and, in particular, for accepting them in combination, or so I have argued.

So I conclude this article in the hope that my proposals of the incompetency model (for civil commitment) and the full responsibility model (for forensic psychiatric care) will provoke some discussion and, eventually, in due time, contribute to a general change of view. Mental illness is just like illness in general, and mentally ill persons should not be treated any differently from people who suffer from somatic disease. Psychiatrists should be given a fair chance of living up to the requirements of the Hawaii declaration and of developing sound professional judgment. Also, a sharp demarcation line should be drawn between, on the one hand, punishment and, on the other hand, care.

All this becomes possible, once the convention is taken seriously.

\section{REFERENCES}

1 Committee of Ministers of the Council of Europe. Convention on human rights and biomedicine. Brussels: Council of Europe, 1996.

2 Rosenau H. Legal prerequisites for clinical trials under the revised Declaration of Helsinki and the European Convention on Human Rights and Biomedicine. Eur J Health Law 2000;7:105-21.

3 Dommel FW, Alexander D. The Convention on Human Rights and Biomedicine of the Council of Europe. Kennedy Inst Ethics J 1997;7:259-76.

4 Tannsjo T. Coercive care: the ethics of choice in health and medicine. London and New York: Routledge, 1999

5 Committee of Ministers of the Council of Europe. Legal protection of persons suffering from mental disorder placed as involuntary patients. Recommendation No R (83) 2:22 Brussels: Council of Europe, 1983.

6 Jensen K. Mental health legislation in Europe. International Bulletin of Law and Mental Health 1994;5:12.

7 Tannsjo T. Hedonistic utilitarianism. Edinburgh: Edinburgh University Press, 1998.

8 Sixth World Congress of Psychiatry. Declaration of Hawaii. Honolulu, Hawaii, 1997.

9 Tannsjo T. Ought we to sentence people to psychiatric treatment. Bioethics 1997; 11:298-308.

10 Beck JC. Forensic psychiatry in the USA and the UK: a clinician's view. Crim Behav Ment Health 1996;6:11-27.

11 Lidberg L. Rä̈tspsykiatrin och farlighetsbedömningar-med erfarenhet som instrument. 8 reflektioner om kriminalpolitiken. Stockholm: BRA, 1999;BRArapport 1999. 